\title{
AUDIÊNCIA DE CUSTÓDIA: PREMISSAS E FUNCIONALIDADES SOB A ÓTICA DO ORDENAMENTO JURÍDICO BRASILEIRO
}

Reginaldo Souza Novaes; Eduardo Buzetti Eustachio Bezerro.

Universidade do Oeste Paulista - UNOESTE, curso de Direito, Presidente Prudente, SP. E-mail:

reginaldo novaes@hotmail.com

\section{RESUMO}

No ordenamento jurídico brasileiro temos o que muitos criticam e apelidam, culturalmente, de "colcha de retalhos", que é a forma como se junta á uma lei existente novas diretrizes, ou alteramse as existentes incessantemente, sem uma maior reforma que sistematize a lei, sejam portarias, resoluções, enfim, atos que não emanam do poder legislativo, mas que legislam, por vezes sob a justificativa da inercia deste, exceção temos no recriado Código de Processo Civil. Nesse aspecto de legislação extra legislativo, falaremos das circunstancias de criação da Audiência de Custódia, quais sejam, os atos do CNJ que a normatizam, em detrimento do poder legislativo, que neste assunto já possui um projeto de lei (554/2011) tramitando para regulamentar do instituto, não obstante, o foco é discutir a finalidade e os empecilhos deste instrumento.

Palavras-chave: Audiência de Custódia; Premissas; Funcionalidades.

\section{CUSTÓDIAN AUDIENCE: PREMISES AND FUNCTIONALITIES UNDER THE OPINION OF BRAZILIAN LEGAL ORDINANCE}

\begin{abstract}
In the Brazilian legal system, we have what many criticize and culturally dubbed a "patchwork", which is the way in which new guidelines are added to an existing law, or alter existing ones incessantly, without further reform that systematizes Law, are ordinances, resolutions, in short, acts that do not emanate from the legislative power, but that legislate, sometimes under the justification of the inertia of this, we have exception in the recreated Code of Civil Procedure. In this aspect of extra-legislative legislation, we will speak about the circumstances of the creation of the Hearing of Custody, that is, the acts of the CNJ that regulate it, to the detriment of the legislative power, that in this subject already has a bill (554/2011) Regulation of the institute, nevertheless, the focus is to discuss the purpose and the obstacles of this instrument.
\end{abstract}

Keywords: Custody Hearing; Assumptions; Features.

\section{INTRODUÇÃO}

Para o cenário de nossa discussão observa-se em principio, que o Pacto de São José da Costa Rica existe há 23 anos, contudo, não era até então observado no aspecto das prisões efetuadas no Brasil, as quais eram em maior volume, sem ainda deixarem de ser, por vezes, de forma viciada, de tal modo que as noticias de abusos policiais são trazidas a mídia e ao conhecimento da sociedade até os dias atuais, sejam prisões ilegais, torturas, etc.

Outro importante aspecto para entendimento da discussão pretendida é a superlotação dos presídios, questão que envolve toda sociedade, pois, infelizmente, sabido é que vivemos numa sociedade violenta, onde há tempos convivemos com déficits em vários segmentos da sociedade, seja de emprego, educação, saúde e tantos outros, problemas que geram mais problemas, contudo não é esta a nossa discussão, o que observamos aqui, vislumbrando a problemática das 
premissas da Audiência de Custódia e suas finalidades, é a já superlotação nos presídios, agravada pelo crescimento e pela perspectiva de continuação deste na numerosa população carcerária, que é em nosso país uma das maiores do mundo.

Trazidos esses pontos fáticos, da normatização fora do legislativo, do abuso policial nas prisões e da superlotação, apresenta-se o último elemento para discussão, os direitos humanos, que são deteriorados pelos elementos já apresentados, mas que são pilares de uma perspectiva de sociedade melhor. Há críticas dirigidas por diversos segmentos da sociedade àqueles que defendem direitos humanos, sem discutir os méritos destas, acredita-se que algumas são entendíveis e outras não, visto que quem critica, o faz sobre um direito próprio, por ser humano que é, esquecendo-se que neste mundo todos estamos sujeito a sorte. Grosso modo, direitos humanos são aqueles que estabelecem conceitos mínimos, que devem ser respeitados em relação ao outro, estabelecendo uma ideia de dignidade humana mínima.

A proposta deste trabalho é, mediante todas essas perspectivas elementares, fomentar discussão sobre a necessidade da Audiência de Custódia, discutindo quais os fundamentos que atualmente a sustentam, de modo a entender a finalidade da Audiência de Custódia, se esta é necessária, e, se sim para que? Se é para garantir os direitos humanos ou a não superlotação dos presídios.

\section{METODOLOGIA}

Na obtenção de dados da presente discussão, quanto a real finalidade da Audiência de Custódia, foi utilizada metodologia indutiva bibliográfica, abrangendo pesquisas de forma a levantar prismas, contextualizar e discutir, de forma crítica, sobre o tema citado, com base em levantamento bibliográfico de doutrinas jurídicas e portarias normativas afins, para leitura e fichamento, de forma intrinsicamente reflexiva, por considerar que a nossa hipótese versa em discutir fundamentos de existência do objeto. A discussão emprega o método hipotético dedutivo, avaliando as posições que sustentam (ou não) o objeto, de forma a buscar o confronto, a fim de analisá-lo com auxílio da dialética.

\section{RESULTADO}

A Audiência de Custódia ou de apresentação é um instrumento da seara penal, a princípio, garantidor de direitos humanos, que vem causando discussões e controvérsias no Brasil. Os entendimentos e materiais sobre o tema ainda não são aflorados, mas necessária se faz a leitura sobre, para que se desenvolva de forma prudente e interessante a discussão dentro da sociedade.

As devidas ponderações e observações sobre esse falso/novo tema, pois não é uma novidade no ordenamento jurídico, mas sim uma revitalização de um instituto até pouco tempo abandonado pela nossa jurisdição penal, são aqui levantadas no intuito crítico avaliativo da proposta.

Os elementos básicos do objeto em estudo podem ser postos, numa forma simplória, em, a apresentação do preso a um Juíz dentro de um curto lapso temporal (contando-se da prisão), sem vislumbrar interrogatório e sem a finalidade de se obter provas ou respostas (que não interessem de forma vantajosa ao réu) apresentação esta onde o réu além de estar perante o Juíz, que não será o mesmo a dar sequência ao processo a ser instaurado por eventual denúncia do Ministério Público (que também ser fará presente), terá ainda a presença de um advogado, tendo a chance de reclamar do procedimento até então, podendo denunciar qualquer ato policial, nas palavras do doutrinador Renato Brasileiro de Lima (2016, p.926):

grosso modo, a audiência de custódia pode ser conceituada como a realização de uma audiência sem demora após a prisão em flagrante, 
permitindo o contato imediato do preso com o juíz, com um defensor (público, dativo ou constituído) e com o Ministério Público. Em prática em inúmeros países, dentre eles Peru, Argentina e Chile, o objetivo precípuo desta audiência de custódia diz respeito não apenas à averiguação da legalidade da prisão em flagrante para fins de possível relaxamento, coibindo assim, eventuais excessos tão comuns no Brasil, como torturas [...], mas também o de conferir ao juíz uma ferramenta mais eficaz para aferir a necessidade da decretação da prisão preventiva

Como dito, destoam entre os autores da área as opiniões quanto utilidade do instituto, há aqueles que de modo pouco tolerado pelos demais acadêmicos indicam ser possível utilizar-se da Audiência de Custódia (ou de apresentação) como meio de prova, o que diverge dos conceitos mais acompanhados e difundidos, que limitam, definindo margens para o instituto, não deixando que o confundam com um de processo iniciado, como aparenta induzir a nota técnica no 1622/2014/-69, do Conselho Nacional do Ministério Público, editada em referência ao Projeto de Lei do Senado no 554/2011 (que tramita para regulamentar a Audiência de Custódia), nesta nota dentre outros posicionamentos, defende-se a utilização em conjunto com outros itens, de finalidades distintas da audiência em estudo, como meio de prova no processo principal, posição esta incompatível com a posição de doutrinadores como Aury Lopes Junior (2016, p. 508), que defende, em contrário, da seguinte forma:

essa entrevista não deve se prestar para analise de mérito (leia-se autoria e materialidade), reservada para o interrogatório de eventual processo de conhecimento. A rigor, limita-se a verificar a legalidade da prisão em flagrante e a presença ou não dos requisitos da prisão preventiva, bem como permitir uma melhor analise da(s) medida(s) cautelar(res) diversa(s) adequada(s) ao caso, dando plenas condições de eficácia do art. 319 do $\mathrm{CPP}$, atualmente restrito, na pratica, a fiança

Aury chama atenção para esse ponto, ensinando que caso não se separe em outros autos a audiência objeto deste estudo, corre-se sério risco de valoração ou desvalorização da mesma, pois que, poderá o acusado questionar fatos que podem instigar o magistrado a desviar de sua função, "o problema surge quando o preso alegar a falta de fumus commissi delicti, ou seja, negar a autoria", (LOPES JUNIOR, p.508). Trata-se aqui, este como ponto crucial para entendimento do instituto, para que, devidamente apartado, o auto não se confunda com processo de conhecimento, sob risco de perda de função e por consequente de utilidade do objeto em estudo, que tornar-se-ia, parte do processo de conhecimento, perdendo assim a natureza fiscalizatória e garantidora.

A resposta pela qual o nome é "Audiência de Custódia" dá-se porque o juíz decide pela legalidade ou não da prisão em virtude da necessidade de Custodiar o preso, ou seja, de mantê-lo cerceado de sua liberdade, que é direito fundamental do homem, neste sentido Renato Brasileiro de Lima (2016, p. 927) sintetiza:

quando a convalidação judicial da prisão em flagrante é feita sem a apresentação do preso em flagrante, ou seja, tão somente com a remessa dos autos do APF à autoridade judiciaria, a decisão judicial acaba sendo influenciada exclusivamente pela opinião da autoridade policial e do órgão 
ministerial, que geralmente se manifestam a favor da conversão em prisão preventiva (ou temporária). Dai a importância da audiência de custódia.

Nesse aspecto de garantia dos direitos humanos do acusado, Renato Brasileiro de Lima defende a presença da Audiência de Custódia em nossa jurisdição, para que exista o contato do indivíduo pessoalmente com o Juíz.

\section{DISCUSSÃO}

Existem sobre o instrumento processual aqui aludido grandes discussões, quanto a sua estrutura e utilização, a que se refere ao prazo para que seja efetuada a audiência é uma das principais, trata-se de uma questão que envolve norma supraconstitucional, que é o Pacto de São José da Costa Rica, onde se expõe que o prazo deve ser "sem demora" ausentando-se de melhor definição em horas ou dias, neste ponto as posições doutrinarias, além do Conselho Nacional de Justiça (CNJ), na tentativa de normatizar diretrizes junto aos estados (meio esse que recebe criticas quanto à invasão de competência para legislar em seara penal), buscam dar forma e norteamentos para jurisdição de primeiro grau, Renato Brasileiro argumenta "o prazo de 24 (vinte e quatro horas) horas não é factível, partilhemos do entendimento no sentido de que a audiência de custódia deve ser realizada num prazo compatível com a realidade brasileira, qual seja em até 72 (LIMA, 2016, p. 928)" sendo este um dos pontos que obstaculiza a aplicação do instituo, tendo em consideração nosso vasto território e suas varias discrepâncias de estrutura jurisdicional.

Nesta discussão sobre a dimensão aceitável do lapso temporal, entre a prisão e a apresentação do acusado a um juíz, tem grande peso a presunção de inocência junto com a regra humanitária de que o direito a liberdade só poderá ser cerceado em situação extrema, de exceção, de ultima opção, quando necessária se for a prisão, numa congruência pela segurança e o justo interesse social.

Neste sentido a fundamentação para aplicação do instituto também entra no rol de discussões. Ricardo Lewandowski, Ministro do Supremo Tribunal Federal é um dos grandes entusiastas e apostadores no instituto, resguarda-se na tese de que a cultura de prender como solução é abominável (R. Lewandowski, Audiências de Custódia do Conselho Nacional de Justiça: Da política à prática 2015), "sob qualquer perspectiva, revela o excesso de prisões, notadamente as de natureza cautelar, determinadas pelo Poder Judiciário brasileiro, dominado por uma cultura de encarceramento", não obstante o Ministro também aponta os números do uso do instituto:

em meados de outubro já contabilizavam a apresentação de 20.836 pessoas presas em flagrante delito a um juíz. Entre esses, 9.852 (45,98\%) acabaram liberados e $11.554(53,93 \%)$ tiveram a prisão preventiva decretada. Ainda: 1.341 (6,25\%) casos de violência no ato da prisão foram denunciados e outros 2.551 (11,90\%) encaminhamentos assistenciais realizados. A repercussão econômica de todo esse movimento também é considerável: dados preliminares apontam que aproximadamente $50 \%$ dos presos em flagrante, quando colocados face a face com um juíz, deixam de ser recolhidos aos já superlotados cárceres brasileiros, estimando uma economia de cerca de $\mathrm{R} \$ 4,3$ bilhões aos cofres públicos, nos próximos dozes meses.

São números que saltam aos olhos, entretanto, não são esses os únicos pilares necessários para utilização do instituto, porque a questão vai além da manutenção da prisão, vai além da questão da lotação nos presídios, pois que, não é porque esta lotado o sistema carcerário que não 
irá mais se prender, não é essa a premissa, ou no mínimo, não pode ser. A questão vai além do direito de cercear a liberdade, a questão em discussão é em torno da necessidade e legitimidade da manutenção da prisão, caso a caso. Parte este estudo da premissa de que o instituto aqui trazido não é forma de resolução da demanda judicial, mas unicamente de prevenção de excessos, ou seja, de natureza cautelar a favor do preso, incidindo na natureza jurídica do instrumento, o que fortalece a ideia de autos em apartado, de não utilização destes como meio de prova.

A audiência de custódia também recebe criticas da doutrina, Guilherme Nucci, respeitado jurista, vem de forma radical em seu artigo "os mitos da audiência de custódia", publicado na sua pagina pessoal e republicado pela pagina do Ministério Publico do Estado do Espirito Santo, fazer duríssimas criticas ao instituto, que considera modismo, do seguinte modo: (G. Nucci, Os Mitos da Audiência de Custódia, 2015):

A experiência de S. Paulo (Capital) conduz para respostas duvidosas quanto a tais estatísticas. Gostaria de saber se os magistrados das audiências de custódia que se realizam, hoje, no Brasil, são todos titulares de cargos fixos. E eles, somente pelo contato com o réu, mudaram sua posição de manter a prisão para soltá-lo. Se alguém me provar isso, gostaria de ouvir do colega juíz o que o réu lhe contou a ponto de sensibilizá-lo, fazendo-o mudar radicalmente de opinião.

A audiência de custódia, com a devida vênia, é um modismo, trazendo vários mitos para serem explorados. Alguns argumentam que ela é a concretização do próprio instrumento do habeas corpus (toma o corpo). Perfeito. Neste importante instituto, há previsão legal para que o juíz/desembargador convoque o preso à sua frente. Nunca soube disso. Se alguém o fez, entra para a estatística mínima, quase desaparecida.

Em suma: a) durante 23 anos, o texto da Convenção Americana sobre Direitos Humanos é o mesmo; somente agora, alguns descobriram que o Brasil o descumpre seguidamente; b) se é um direito humano fundamental, em todos os lugares onde não há audiência de custódia, os flagrantes devem ser imediatamente relaxados, pouco importando o caso concreto; c) se juízes precisam conversar com o réu para dar-Ihe algum benefício, devemos transportar o interrogatório novamente para o início da ação penal; (...) STF tem a tendência de equiparar tratados a lei federal; de todo modo, mesmo que se considere a referida Convenção acima de qualquer lei, segundo nos parece, quem deve legislar sobre o procedimento nacional a ser adotado para a audiência de custódia é o Poder Legislativo e não o CNJ, nem qualquer Tribunal Regional ou legalidade, que vem sendo vilipendiada por um Estadual. A isto se chama número excessivo de portarias, resoluções, provimentos e similares, originários dos mais diversos órgãos, sem o menor apego à função do legislador em matéria de direito

Apesar da forma extrema como Nucci encara o instituto é de se apreciar seu posicionamento, considerando que na medida em que o instituo muda o curso do tratamento ao preso, cabe a discussão da efetividade perante os moldes da estrutura jurisdicional brasileira, assim aponta-se aqui como cruciais os pontos levantados nesta fala, no que se refere a finalidade do instituo e aos personagens e seus poderes-deveres, dentro da jurisdição penal. 
Nucci ainda tece sobre a audiência de custódia criticando o que coloca como não aceitação pelos defensores do instituo que o delegado seja aquele a conferir legitimidade à prisão (num primeiro momento) sendo que este é bacharel em direito, aprovado em concurso público, conhecedor das leis, que poderia continuar, por escrito a encaminhar apenas o auto de prisão em flagrante (sem a necessidade de presença frente a frente, réu-juíz), na forma como se tem pratica forense de 23 anos, em suas palavras (Nucci, 2016, p. 736) "afinal, apresentar o preso ao Delegado de Polícia não é o mesmo que apresentar ao Juíz de Direito, então "criaram" a audiência de custódia [...] ora os defensores da audiência de custódia não aceitam o Delegado [...]".

Fomenta ainda, de forma incisiva, que a finalidade do instituo é muito mais ligada à resolução de um problema em aberto do Estado, qual seja a superlotação de presídios, do que a busca por condições mais humanas e garantidoras de direitos aos encarcerados, repetindo ainda, que o instituo em questão não é novidade na seara penal, mas que permanecera adormecido por longos 23 anos, sem que houvessem contestações.

\section{CONCLUSÃO}

Conclui-se que a Audiência de Custódia é um instrumento que apesar de poder inibir abusos em procedimentos policiais, pelos contrapontos aqui expostos, aparenta transferir a condução da prisão em flagrante do delegado de polícia ao juíz por meio de normas extra legislativas. Por esse e outros motivos, acredita-se ser necessário nova análise sob perspectivas jurídicas e práticas, questionando a necessidade, principalmente considerando que estamos na expectativa de um novo Código de Processo Penal, afim de que até lá possamos estar pisando sob conceitos firmes deste instituto, o qual não poder ser utilizado para resolver o problema estatal de segurança pública, pois isto seria um erro inadmissível, já que resultaria em riscos, e ainda, argumenta-se que há o aumento de carga jurisdicional sobre juízes, MP e defensores, não obstante e de forma mais preocupante, aparenta o instituto que passa a existir limitação de funções do delegado, por fim, critica-se que o prazo de 24 horas para apresentação do preso ao juíz é fora da realidade brasileira.

\section{REFERÊNCIAS}

CAPEZ, Fernando. Curso de Processo Penal, 23ạ edição, Saraiva, 2015.

LEWANDOWSKI, Ricardo, Audiências de Custódia do Conselho Nacional de Justiça: Da política à prática 2015, disponível em: <http://www.conjur.com.br/2015-nov-11/lewandowski-audienciascustódia-cnj-politica-pratica > acesso em 29 de março de 2017.

LIMA, Renato Brasileiro de, Manual de Processo Penal: volume único/ Renato Brasileiro de Lima 4 ed. rev., ampl. e atual. - Salvador: Ed JusPodivm, 2016.

LOPES JR, Aury, Direito Processual Penal - 13 ed. - São Paulo: Saraiva, 2016.

NUCCI, Guilherme, Código de Processo Penal Comentado, 15 ed. rev., atual. e ampl. - Rio de Janeiro: Forense, 2016.

\footnotetext{
- Os Mitos da Audiência de Custódia. Disponível em: $<$ http://www.guilhermenucci.com.br/artigos/guilherme-nucci/processo-penal/os-mitos-daaudiencia-de-custódia-2>. Acesso em 29 de março de 2017.
} 